\title{
SOME REFLECTIONS ON THE ORIGINS OF COGNITIVE LINGUISTICS
}

\author{
ENRIQUE BERNÁRDEZ \\ Complutense University of Madrid
}

\begin{abstract}
The purpose of these notes is to contribute to the understanding of the intellectual and scientific origins of Cognitive Linguistics (CL); it is not, therefore, a history, even partial and incomplete, of $C L$; neither does it offer any exhaustive consideration of all the factors, influences, linguistic and psychological models, or of all the linguists that have contributed to the birth and development of the discipiline, an enterprise that is probably premature.
\end{abstract}

\section{INTRODUCTION}

Cognitive Linguistics is something fundamentally different from any of those "one thousand and one theories of grammar" which seem to exist in the field. HDPSG, RG, WD, LFG, even MG (Chomsky's Minimalist Program) exist as basically separated approaches to grammar and language which share just a few common ideas of a very general nature at the most: maybe that language is considered as a 'somewhat' autonomous mental component or module and that only that part of grammar which can be independently studied and described merits serious attention as the nuclear part of language. But the methods, including the different approaches to formalisation, are quite different, some restrictions operating in some models but being flatly rejected in others; for instance, the possibiliy of assuming the existence of categories like PRO or pro which per definitionem lack any phonetic realisation, is nowadays only accepted within 
MG. It is even doubtful whether it would be right to use the term formal grammars as referring to these divergent models in any but the most trivial sense.

In contrast, CL seems to allow for the existence of a number of different approaches, always considered as partial, which are seen as integrating a more general framework; this framework exhibits some characteristics which are adhered quite consistently to by the proponents of the different schools or models and it extends to the formal thinking underlying them. This diversity is moreover naturally accepted: the different models devote themselves to particular aspects, or subfields, of what is accepted as the common framewok of CL (which is moreover part of a yet wider field, Cognitive Science). There exists a significant number of principles that seem to be shared by the individual models and even, I dare say, by some of the more 'formal' approaches.

This enables the existence of 'textbooks on CL' in a sense quite different from the usual one in 'introductions to linguistics', something that is in fact quite new in the recent history of our discipline. The existing self-called 'textbooks' have been restricted to the presentation of one single model or theoretical approach, more frequently than not that of Generative Grammar (GG), and if someone wanted to acquire a wider knowledge of what was being done in linguistics, she had to use a number of different, partial books. Even within GG the usual case was to restrict oneself to the model then considered as orthodox, perhaps with some scattered references to other generative approches, as is the case in Peter Culicover's (1997) Principles and Parameters who readily uses the results achieved by LFG and RL; it has to be said, however, that such results are sometimes taken advantage of by the proponents of the standard GG model but without quoting them (see Pullum 1991).

A recent textbook as Friedrich Ungerer's and Hans-Jörg Schmid's (1996) An Introduction to Cognitive Linguistics is a clear case in point. This book is organised around a number of what can be called 'basic issues' of CG and not on the differences among the approaches or on the presentation of alternative explanations of the same facts: Prototypes and categories, Levels of categorization, Conceptual metaphors and metonymies, Figure and ground, The Frame and attention approach, and Other issues including Iconicity, Grammaticalization, etc. What is new is not this subject-centered approach, which is also visible e.g. in Culicover's introduction to GG: Arguments, government, and case; Binding theory; A-Movement; $X^{\prime}$-Theory, etcetera. What I think is really new is first that the chapters in Culicover's book or in any other introduction to GG, are devoted to issues concerning one single model, so that if we should take a different one, say HDPSG or LFG, some of them would necessarily have to disappear: there is no place for chapters on $X^{\prime}$-Bar Theory or A-Movement in a textbook in HDPSG, for instance. The basic issue is not whether $X^{\prime}$-Bar Theory may play a less relevant role 
in HDPSG, and that such an important place in a textbook is deemed as unnecessary, but that it plays no role at all: it simply does not exist.

The chapters in Ungerer and Schmid's book (U\&S), on the other hand, would be acceptable to anyone inside CL, even if some of them would not play such an important role in some models as in others. But the difference Figure-Ground is universally accepted, as is the importance of Prototypical Categorization, and so on. Let us recall the main chapters in any general introduction to any other scientific field, e.g. biology. It would make no sense to be obliged to write a different introduction to Biology for every possible approach, or that some chapters should only make sense in the framework of a given approach. The same chapters would have to be found in any general introduction, say Molecular biology, Cellular biology, Organismic biology, etcetera, and even books devoted to any one of these subdisciplines would share a basically similar structure. Now, not everyone in molecular biology works on the same issues or is even interested in all the aspects of the discipline, much less in biology as a whole, but they agree on some fundamental findings and frequently work on the results and achievements of other biologists. As I see it, this is what is happening in the reorganisation of linguistic studies that is known as CL.

$\mathrm{CL}$, in fact, has not grown out of the work of an individual, as has been the case in practically all the other modern linguistic models and especially GG, which has a clear point of departure with the publication of Chomsky's Syntactic Structures in 1957, which was itself a development of another individual linguist's ideas: those of Zellig Harris. Systemic Grammar is clearly associated with Michael Halliday, Functional Grammar with Simon Dik, etcetera. For these schools precise dates of birth can be given but, on the other hand, who, if anyone, was the initial creator, instigator or whatever of Cognitive Linguistics? Several people working in different towns, at different Universities of different countries coincided at some point in a number of basic ideas of language which, moreover, were also independently shared by a number of psychologists, biologists... even mathematicians with an interest in both biology and language (as is the case of the French René Thom). This makes CL, as has already been pointed out, quite different from the countless models, submodels, theories or subtheories of language and grammar that have appeared in the last fifty years or so. The only similar case, to my knowledge, is that of Textlinguistics -as opposed to Discourse or Conversation Analysis, Ethnomethodology, etcetera-. Textlinguistics (TL) also emerged as the result of the efforts of a number of unrelated linguists working independently in different parts of the world; we could say that they "did not know they were doing textlinguistics" until they began reading each other and discovered that their interests and even sometimes their methods were closely related. TL, however, is only a partial study of language, as it has traditionally focused on only a few aspects of it, and 
not on language as a whole. However, if the recent history of TL is considered (see e.g. Heinemann \& Viehweger 1991), the interests of this discipline have frequently coincided with those of a general theory of language in a cognitive framework; again, with no direct relation with what was being done at the same time by linguists that called themselves 'cognitive'. I shall come back to the relations of TL and CL.

Of course, there exists a number a people who played a fundamental part in the creation of CL as we know it today and, especially, of the partial theories within CL that enjoy the greatest popularity. In fact, within CL several, sometimes rather divergent approaches can be distinguished. What follows is a non-exhaustive list and sometimes, for the lack of a good denomination, a linguist's name will have to be used alone:

Cognitive Grammar as represented by Ronald Langacker.

Construction Grammar (Fillmore, Kay, etc.).

Lakoff's (and many others') work on metaphorical categorisation.

Prototype theory.

Mental Spaces Theory (Gilles Fauconnier).

Leonard Talmy's work (which could be termed Framing-Theory, following U\&S).

Jean Petitot's recent work within the framework of dynamic theory and mereology.

Wolfgang Wildgen's imagistic grammar.

Jean-Pierre Desclès' cognitive approach to language and grammar.

Although not immediately included in CL, also Culioli's approach shares many features with these models, as do most recent developments of Simon Dik's Functional Grammar. Even HDPSG, traditionally considered as a branch of GG, has been getting closer and closer to CL.

\section{COGNITIVE Linguistics HAS A VARIETY OF SOURCES}

But a linguistic theory or a linguistic model does not grow out of nothing, it is the result of both internal developments within the discipline and of the general scientific ambience or in more general terms: of the ways of thinking at a given time. As we shall see, CL seems to be a result of two lines of thinking within linguistics: on the one hand, the insatisfaction with the results of research within Generative Grammar (GG), which made it impossible to understand and describe in an adequate form some issues that were however considered as of great importance; on the other hand, developments in textlinguistics necessarily lead, even in the first years of this discipline, to positions now generally acknowledged as cognitive. CL is also the result of some general trends in thinking: both the acceptance of variability, flexibility, and the need for a subtler means 
of analysis than that provided by GG, which should be able to tackle the study of certain linguistic phenomena now deemed important but previously left out of the centre of interest. And, secondly, certain characteristics of contemporary thinking, related to that general trend usually called 'post-modernist thinking', visible in such things as a vaguer but at the same time subtler way of tackling complex problems, recognising the role of variation etc., and also the generalisation of a topological way of thinking.

\section{ON IDEALISATION, SIMPLICITY, AND REGULARITY}

One of the reasons for the emergence of CL and one of its most significant features nowadays is a special interest in those aspect of language that were previously considered as irregular or marginal and, as such, have lacked adequate treatement. Linguistics has traditionally devoted its main efforts to what was considered as mainly systematic, regular, the rest beeing dismissed as 'exceptional' and therefore of little significance.

As John Ellis (1993) wrote:

...linguistic theory has been hampered by a general misconception about scientific procedure - the assumption that we proceed from the simple to the complex, from the known to the unknown, from the unproblematic to the difficult. The result of this approach to problems in any field is that the unknown is likely to stay unknown, and that what is difficult and complex will stay that way because the concepts we have derived from the apparently simple cases were inadequate; we have in effect made sure to start out with a theory that must by definition have excluded a large set of cases. What trips us up here is an overconfident view of what we thought was "the known", that is, those cases for which we think we already have a coherent view. [p. 73/4]

This is clearly visible in the generative approach to language; let me quote from Robert de Beaugrande's (1991) remarks on some important works in the recent history of linguistics; when considering Chomsky's approach to language and particularly to the study of performance, he writes:

Chomsky's reasoning leaves it unclear just how 'a study of performance' might 'investigate the acceptability' of 'sentences' or how a grammar could test its claims about 'speakers' rejecting' 'sequences as not belonging to that language'. He postpones the problem by relying on 'clear cases' (preferably 'violating purely syntactic rules' rather than 'semantic or "pragmatic", ones), by not 'appealing' to 'far-fetched contexts', and by promising that for 'intermediate cases' we can 'let the grammar itself decide' once it is 'set up in the simplest way' to 'include clear sentences and exclude clear non-sentences'. [p. 162: 7.42] (My emphasis in italics) 
In Semantics, those words first selected for study, those considered susceptible to be studied in any scientifically sound way, are the words which have a precise, relatively simple meaning, as opposed to those which are 'excessively' complex or whose meaning varies a lot and appears as more diffult to analyse in any systematic way. The consequence was that the 'real' part of the vocabulary was left out of the considerations of linguistics (see Bernárdez 1998a).

On the other hand, and also as a consequence of the strife for simplicity that characterises most linguistic models. words were assumed to have clear counterparts, or referents, in the real world, this being the default assumption when confronted with meaning, in the spirit of the Tarskian definition of truth: "it rains is true iff "it rains"". But, to quote John Ellis again:

Realists often suppose that the only cases of words that do not show clear and defining physical criteria for their use are the grosser evalutative words such as good or bad, but this is by no means the case. Most of the basic words we live by are from this realist standpoint amorphous categories: food, shelter, clothing, poison, weedes - all of these are categories clearly held together not by physical identity but by functional equivalence. [p. 31]

In fact, one can say that the predominance of 'realistic semantics' was simply due to the need to find clear 'counterparts' to meaning, in the sense of the previous quotes. This was done even when it could be quite clear that such procedure might render linguistic study fairly irrelevant to the reality of language. Idealisation, as a basis of scientific thinking and methodology, was brought to its limits by Chomsky (see Bernárdez 1995) in an attempt to isolate what he thought was 'simplest' in language and therefore (erroneously) taken to reflect its deepest reality. In this extreme idealisation, Chomsky tried to implicate earlier linguists, but:

Chomsky's clearest tribute to his predecessors in a bit inaccurate, namely when his 'idealization' of 'linguistic theory being primarily concerned with an ideal speaker-hearer in a completely homogeneous speech community' is depicted as 'the position of the founders of modern general linguistics' (AT 3f). Perhaps Hjelmslev is meant, who contemplated 'eliminating' 'accidents' and 'disturbances' 'in the exercise of language' (in 'parole') (PT 94) (6.46), but he had no 'speaker' or 'hearer' at all. Otherwise, the modern founders I have reviewed were, on the contrary, much concerned with the issues of variety and change in language communities. [182: 7.96]

It can be said that GG owes its methods and even its basic ideas in great part to the need, then considered as scientifically unavoidable, of restricting our analysis of language to the simple, ordered, regular cases: there existed, and still exists within 
'orthodox' GG, even in MP, the idea that linguistic phenomena are strictly regular; as regularity is associated with simplicity, only simple phenomena being able to be seen as fully regular, 'mainstream linguistics' avoided irregularity and therefore complexity: the creation of the simplest possible grammar for a language is one of the main aims of linguistic research.

\section{LAKOFF'S 1965 ANALYSIS OF IRREGULARITIES IN SYNTAX}

But still within the first orthodox model of GG, the 1965 'standard theory', problems related to regularity began to be detected. George Lakoff's 1965 dissertation bears the interesting title of Irregularity in Syntax and can be seen as one of the main predecessors of 'generative semantics' leading directly to CL. Lakoff wrote:

Originally, it was thought that all syntactic rules, including grammatical transformation were "regular" - that their applicability was determined solely by the occurrence of natural grammatical categories. In such a system, "irregularities" were impossible, and any apparent irregularities were assumed to reflect the existence of hitherto undiscovered natural grammatical categories. Recent attempts to account for apparent irregularities, however, have resulted in the postulation of a large number of grammatical categories that are anything but "natural". A great many of them have had to be postulated only to account for the peculiarities of individual lexical items in their interaction with isolated rules in a single language. These results suggest that the original assumption was wrong and that irregularities are a normal part of language. (Lakoff 1970: xii) (My emphasis in italics).

Now let us remember that one of the most string features of GG is the postulation of categories which lack any phonetic realisation, such as PRO and pro, SUBJECT, etcetera. This has become one of the main points of disagreement between GG and other, even formal, models: for instance, both Functional Grammar (FG) and HDPSG reject the possibility of postulating such empty categories. This seems a purely formal issue: whether recognising the 'existence' of such empty categories is necessary or not for the construction of the 'simplest possible grammar' of a language and the simplest grammar of all, Universal Grammar, but this is far from being the case and its implications are much more far-reaching.

Lakoff's book was of crucial importance for Generative Semantics, but a clear line can be drawn from it to modern CL. The problem of syntactic irregularity associated with individual lexical items has many significant implications. As Lakoff himself points 
out, this issue is very much related to the place where 'lexical insertion' took place and correspondingly to the nature of 'deep structure'. Lexical items, according to Lakoff's 1965 proposal, are superficially inserted, not pre-transformationally as was then assumed. This means, on its turn, that the deep structure should contain some sort of universal semantic elements or, in other words, that it is semantic, not syntactic, but also non-lexical. This is well-known from the developments of later Generative Semantics but it also can be seen as one of the fundamental tenets of CL and other models, such as FG: the generation of sentences has to begin at a semantic level, which is (relatively) universal, the individual lexical items being a matter of the individual languages, as are the syntactic structures.

\section{SOME IMPLICATIONS OF 'ORDER' AND 'REGULARITY'}

Let us deviate a little from the main argument and consider some unexpected consequences of the absolute importance of regularity. Irregularity is seen as a 'deviation from what is normal', under the assumption that linguistic phenomena are basically regular and well-defined, thus simple (simplicity having to be understood in computational, algorithmic terms): this reflects the deep idea of a simple, regular, wellorganised world which is only disrupted by phenotypic variation: the world is deep underlying order, only its imperfect surface realisation is unordered, apparently random.

This is also Chomsky's underlying idea in political issues, based on the conception of the human being as an inherently, universally 'good' creature, endowed with goodness by nature itself, as opposed to their faulty, bad ways of acting when their essential goodness is disrupted by economic and political considerations. Compare this with the 'perfect organ' of language (Chosmky 1992) disrupted and spoilt by the conditions in which linguistic communication, language use, takes place ('performance'): only through introspection (looking at our own internal reality) can we get at the deep reality of language and empiristic studies of linguistic phenomena will more often than not only serve to disrupt our view of language: in the Minimalist Program, empiric analysis plays a very secondary role, the aims of linguistic theory being now those of discovering the conceptually necessary characteristics of that internal, universal, ordered and perfect human language $\left(L_{i}\right)$ (cf. Chomsky 1986). In this well-ordered world of language there can be no room for irregularity or, in other words: Universal Grammar has to be regular, irregularity only appearing at the superficial level of individual languages $\left(L_{e}\right)$. Order would be at the level of the genotype, irregularity belonging to the phenotype. 
Now let us suppose that this is not necessarily true, i.e. take a more neutral, less prejudiced stand-point: if we assume that human beings are determined by their genetic endowment but also by their background, their environment, irregularities, i.e. lack of order can be expected anywhere. When Chomsky rejects the idea that biological (or psychological) reality must be a criterium for the validity of a linguistic model, he is in fact reacting against the discovery of inherent irregularity, or chaotic behaviour, in any biological organ, hence his preposterous claim that language is the only perfect organism, just to save his basic proposals.

CL, on the contrary, usually faces quite complex and apparently irregular phenomena which somehow show chaotic behaviour. This is the case for instance in Lakoff's (1987) famous analysis of the noun classes of Dyirbal; although his analysis does indeed shed a lot of light on how noun classes can be organised in a language, in an extremely complex form as many different factors may intervene, there is still room for irregularity, seen as a necessary, unavoidable component of language; in the same way as there exists endless variation among the individual human beings or any other biological organisms, variation and irregularity can also be expected to exist in language: we have given up the hopes that absolutely everything can be satisfactorily explained. This is an underlying principle in all of CL thinking and also one that has been at the origin of a great number of acrid criticism and accusations that CL lacks any sound scientific background. In CL, as in modern thinking in general (including biology, on which more will come later), variability is fully accepted as natural and there exists no artificial restriction of our efforts to those (aspects of) phenomena which seem to show a lower degree of variability. If, as we saw in a preceding quote by de Beaugrande, Chomsky proposed to start the study of performance by considering only the clear-cut cases, excluding 'far-fetched contexts' the situation in CL is quite the opposite: you need just consider the contextual conditions assumed for the interpretation of quite a number of the examples discussed in most journal articles ${ }^{1}$.

\section{IRREGULARITY IN SYNTAX AS A FIRST STEP TOWARDS COGNITIVE LiNGUISTICS}

To come back to some of Lakoff's 1965 proposals, the lexical base hypothesis then (and later) assumed involves e.g. that 'synonyms would have the same lexical bases that is, they would have the same deep structure distribution and any differences in surface structure distribution would be due to differences in their lexical extensions' (p. 110). To use his own examples, consider the following sentences:

1. Just have a look at Fauconnier's or Lakoff's examples. In a paper by Claudia Brugman, understanding a sentence needed knowing the base-ball teams in Oakland and the San Francisco Area. 
1. a. Writing papers is difficult for me.

b. Writing papers is hard for me.

2. a. My difficulty at writing papers.

b. *My hardness at writing papers.

At the time, some transformations were postulated that would keep the same syntactic relations in 1a and 2a. But everything that could be said about difficult would also be possible for hard, as they are synonyms as seen when comparing 1a. and 1b, but that is obviously not the case as is shown by $1 \mathrm{~b}$ vs. $2 \mathrm{~b}$. But if $1 \mathrm{~b}$ is possible and $2 \mathrm{~b}$ is not, then difficult and hard cannot share the same lexical base, and the only way out is to consider hard as behaving irregularly².

In page 111, Lakoff writes that the lexical base hypothesis would also imply that words that are synonyms in one language will also be synonyms in (all the other) languages: '[I]f a lexical item in Language A is synonymous with one in Language B, the lexical base hypothesis would claim that the two items have the same lexical base. Thus, grammatical information about one language would be quite relevant to the grammatical analysis of another language'. The lexical base hypothesis, although in a form that does not correspond to Lakoff's original proposal, has led to certain developments within standard GG that seem rather bizarre to say the least, as Jerry Fodor's proposal of Mentalese which starts from the underlying idea of the existence of 'real' lexical items genetically imprinted in our brains (ultimately as a consequence of the impossibility of learning that subtends everything in GG).

As is well-known, CL takes quite a different stance. Beginning with the generative semanticists' proposal of understanding lexical items as composed of smaller units (the famous kill = cause to die), a stage was reached where the individual lexical items can only exist in individual languages, the universal semantic base being composed of other, more general elements, variously denominated as frames, mental images, etcetera. In this sense, a very interesting remark by Lakoff can be understood:

Someone (...) Who does not know a word of Hungarian can be completely certain that the Hungarian verb meaning to hate takes animate subjects and that the Hungarian verb meaning to believe takes animate subjects and abstract objects.

2. I am changing Lakoff's argumentation a litlle bit, in view of the later development of his ideas. In fact, what he intends to do in this section of his book is to offer arguments for a lexical base hypothesis which is, however, different from the form it would take later within GG. Lakoff's main idea in this chapter seems to be in the direction of seeing semantics, as opposed to syntax, as the base generative component, an idea which was later developed within Generative Semantics... and that is commonplace now, even, in a sense, in the Minimalist Program. 
This is a very deep fact about language which the lexical base hypothesis could explain. (op. cit., p. 111)

One can recognise here the usual way of understanding the ultimate base of grammatical constructions (including the lexis): some form of (real world?) reality that, while forming a unit, is analysable in further elements. In CL, a certain base frame, mental image, etc. can be reflected in a clause including a verb like to hate, but not due to any lexical properties of the word hate itself: a hater and a hatee form a necessary part of the corresponding frame, not necessarily of the verb, which can superficially lack any 'object' representing the hatee. In GG, even in the MP, it is the lexical properties of a word that form the base for (syntactic) derivation: the VERB to hate has a structure of the type: hate $(x, y)$, a standpoint which has a lot of interesting consequences. For instance, that verbs that can be both transitive and intransitive must have two different lexical bases: there has to be a verb $\operatorname{run}(x)$ and a different verb $\operatorname{run}(x, y)$ : they are in fact assumed to be two different words. In the case of sentences 1 and 2 above, as the syntactic behaviour of difficult and hard are different, they have to be seen as being syntactically and lexically different, thus leaving the synonymy of $1 \mathrm{a} / 1 \mathrm{~b}$ unexplained.

Consider also the much-debated problem of verbs with and without a double object construction, with its consequences in passivisation:

3. a. He gave her a book / She was given a book.

3. b. *?He donated the library a book / *?The library was donated a book.

If both apparently synonymous verbs behave differently, they have to be different in the base, so that arbitrarily different definitions have to be provided for each verb. Compare the quite different approaches to the problem in orthodox 'syntacticist' GG (as Culicover 1997 or Radford 1997), and a cognitive approach as that of Adele Goldberg (1995; see also Jackendoff's remarks (1997: 175-176)).

As Lakoff pointed out, the solution for such irregularities was usually found 'in the postulation of a large number of grammatical categories that are anything but "natural" (1965: xii). The problem of irregularities, then, proved impossible to solve within the conceptual framework of GG and lead to a fundamentally different view which would in time, when set in a wider framework, become 'cognitive'. This is of course the scientific method: finding coherent explanations for what is left unexplained in the standard theory. Lakoff's study of irregularities lead to some very important new insights in linguistics, which James McCawley lists in his foreword to the book. The most important one for our purposes here, is that 'he cast great light on the concept of "grammatical category" by showing that the great profusion of category labels that had appeared in previous transformational work could be avoided and the inventory of categories reduced to a set that could lay some claim to universality.' (Lakoff 1965: v). 
Just a little reflection on this remark may suffice to identify in this book, over thirty years ago, some of the main features of any cognitive grammar, as well as the point from which quite a number of fundamental contemporary insights were developed.

\section{COGNITIVE PRINCIPLES VS. LINGUISTIC PRINCIPLES}

In fact, any partial CL model is characterised by the postulation of a very small number of general principles which are moreover assumed to be universal in that they should correspond with some basic principles of human cognition. This recourse to cognition as the ultimate basis of language, instead of the postulation of some strictly 'linguistic' principles, allows a greater explanatory power of CL as compared with previous models: to state it shortly, "language is thus because human cognition is thus". Now, compare the general cognitive principles used in CL with those of the Principles and Parameters model of GG. One such cognitive principle is the one underlying the creation of mental spaces in the sense of Fauconnier; another one, which Lakoff has shown convincingly to be useful for many areas of human cognitive activity in addition to language, is that of metaphorical reasoning; compare also the small set of universal principles proposed by Ronald Langacker. On the other hand, take the first principle of Binding Theory (binding condition nr. 1): An anaphor must be bound in its domain. Apart from its supposed ability to explain certain linguistic constructions, this principle is not valid in any other area of cognition; it is -and it has to be, given the generative framework- of exclusively linguistic validity. But as Karen Van Hoek has shown in her recent book on anaphora (1997), the same facts can be explained using more general principles which are also valid for other areas of human cognition: conceptual distance, connectivity, etc, which also play an important role in perception (see also Bernárdez (to appear)). Even the principles in MP, which look very much like having a general cognitive validity, are (somewhat artificiously, I think) considered to be exclusively linguistic; even the general principle of economy: it should have nothing to do with a similar principle that is active everywhere in human cognition and activity.

\section{SOME ULTIMATE RESUlts OF LAKOFF'S BOOK}

A line of thinking can be drawn directly from these early ideas of Lakoff's to the following current ones:

1) Semantics is the basic, initial component and it determines the syntactic structures.

2) The meaning of lexical items has to be understood as somehow 'composed' but not in the sense of traditional, structural compositional semantics, but as the representation of some 'pre-linguistic' mental images. 
3) The semantic component is universal.

4) Some deeper, 'natural' explanation must be attempted for what is apparently 'irregular' without having to posit artificial categories for the behaviour of idiosyncratic elements (however, as we shall see, there is plenty of room for idiosyncracy).

In 1965 it was impossible to find a general framweork which could explain facts like those presented above for the syntactic realisation of semantic structures, for instance for the argument structure of a verb like to hate, to continue with Lakoff's example, and the theories of mental images or frames would have to wait.

\section{THE TOPOLOGICAL APPROACH AND THE ROLE OF TOPOLOGY}

However, even at such early date, some proposals were being made which, if taken advantage of, could have accelerated the process. That is the case of René Thom's archetypes, a consequence of his own application of his dynamic theory, usually called Catastrophe Theory, to some linguistic issues. Thom's ideas had little chance of being known and accepted in linguistics, as he is a mathematician, his linguistic knowledge is rather limited and, moreover, as he published in journals rarely read by linguistis. The situation was even worse in the English-speaking world, as he usually wrote in French and the remarks on language and linguistics were excluded from the English translation of his 1966 book. The archetypes can be seen as a formal representation of the ultimate basis for image schemas, mental images, and frames, as I have tried to show in several papers (Bernárdez 1994, 1995b, 1998a), and they give a coherent, 'natural' explanation for the number and nature of the participants in a process. For instance, the verb to hate, which involves a human first participant and a second participant of any kind can be ultimately be represented with the following archetype:

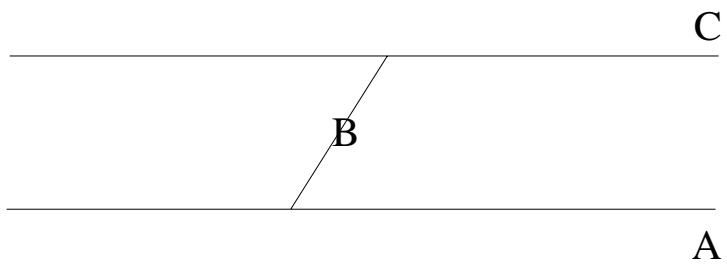


This could be defined in the following way: 'In the space of mental activity (different 'spaces' are assumed in Thom's approach) an entity A realises an activity B which affects another entity $\mathrm{C}$ but in such a way that both $\mathrm{A}$ and $\mathrm{C}$ continue to exist in space-time after B stops.' The meaning of the verb is the whole process, which cannot be understood in the absence of its participants.

Place does not allow a deeper consideration of Thom's ideas which can be seen as foreboding much in cognitive linguistics. In fact, the scarce linguistic reception of his works emphasised some points which seemed unacceptable still in the early seventies but which are a part of CL nowadays, such as the idea of the existence of diverse spaces and relations among them, which anounces some much later ideas of Gilles Fauconnier, or Lakoff's invariance principle (see Lakoff 1991), identifiable in Thom's conception of the fibred spaces or in Fauconnier's (1997) blended spaces. But where did Thom take his ideas from? Of course not from linguistic work, by himself or others. René Thom worked on topology and wrote quite a number of papers on the philosophical implications of looking at the reality and especially the biological world from a topological standpoint instead of the traditional logic one. He devoted in fact a lot of work to 'theoretical biology' in a sense that fits some recent ideas on the general behaviour of complex biological beings and particularly the theory of evolution.

\section{Cognitive Linguistics And Biology}

Now, it may be interesting to point out that CL sees language in close relation to biology and that, inversely, some modern biologists find in CL quite a few paralleles with their own work. A case in point may be Gerald Edelman (1992) who quotes Lakoff's and Langacker's work as the linguistic solution of certain problems also encountered by biology and the structure of the mind. Interestingly enough, his books had the consequence of provoking an extremely unscientific (and even unethical) reply by Chomsky (1992) who, unable to accept that CL (whose mere existence he bluntly refuses to accept) may be right where he is wrong, crucially alters Edelman's explicit statements while, at the same time, positing the 'unique' character of language -in his own view- as the only 'perfect' biological organ and, moreover, he writes that it is up to biology, neurobiology, and information science to keep pace with the discoveries made by linguists, and not viceversa.

Anyway, viewing language (again) more in terms of the biological organisms than of the physicial phenomena, is an apparently secondary feature of CL, which is closely related to the cognitive element in this approach which, obviously, has to face the biological reality of the brain. But let us remember the significant role played nowadays 
by biology even in our daily lives: biological issues ranging from evolution to molecular biology, genetics, ecology etc. are subjected to constant attention and interest by the media, and many divulgative texts on various biological issues enjoy considerable popularity. The last twenty years or so have indeed experienced a shift in the main scientific interest, biology having become the science of today, as physics was the model science when Chomsky began his work in GG.

\section{ToPology + Biology + Cognition: THE GeStALT}

René Thom, then, applied his topological thinking to biology and also to language, as he thought to be able to identify the same basic structural principles in both. For instance, in the fact that the biological organisms are complex units, as are also the linguistic phenomena. That is, the idea of form as a unitary and at the same time compositional phenomenon lead to something extremely similar to the idea of the linguistic gestalt which was introduced in linguistics by George Lakoff and Leonard Talmy in 1977. In fact, everything in CL is topological in nature, from Lakoff's relations among metaphorical domains or his Invariance Hypothesis (1990), Fauconnier's Mental Spaces, Langacker's CG, initially called Space Grammar, to the manifestedly topological formalisations used by Declès (see Desclès \& Kanellos 1997), not to mention those used by Wildgen, Brandt, or Petitot who claim to be using topological formalisations.

In this point, as in so many others, CL shares a development that is visible throughout the spectrum of modern thinking: entities, including categories, are not seen as closed, well-defined entities, but as more subtle, flexible constructions (forms, see Bouligand et al., 1994): precisely what we usually refer to in linguistics (and in areas of cognitive psychology) as a gestalt. Topological thinking has also been applied to literary studies, to quote just a neighbouring example (see Guerra (to appear)).

As we see, two different, at first apparently unrelated ways, lead to the same point: the analysis of certain linguistic constructions with the means available in 1965, which were logical and algebraic in nature, and the reflection on linguistic issues from a topological (i.e., non logical, non algebraic) perspective.

This development, as I have already pointed out, is a part of modern thinking and makes CL 'fully contemporary' from a general, say philosophical, point of view; let us remember that GG was born in a particular intellectual ambiance, that of the middle fifties, and was also 'fully contemporary' by then; unfortunately, GG did not keep pace with the times in this respect as in so many others. I shall not enter here into a comparison of the basic ideas that serve as a background for CL and modern 'postmodern' thinking, but their similarities can be seen, upon a bit of reflection, to be truly striking. 


\section{TeXtLinguistics OR HOW COGNITIVE STUDIES BECAME A NEED}

A large part of modern Textlinguistics (TL) also started in GG trying to answer certain questions on intrasential relations. As no possible satisfactory answer could be achieved within that framework, new methods and conceptuals tools had to be created. An important part of the linguistic analysis of texts was their semantics, in particular how certain semantic-pragmatic relations could be explained that also involved some syntactic features of the individual sentences, such as the selection of the definite article and many others. The type of semantic analysis necessary for TL involved recognising the lack of a net distinction netween 'linguistic' and 'encyclopaedic' meaning, as well as a separate consideration of meaning (seen in rather abstract terms) and sense (the realisation of meaning in a text). Thus, the meaning of words had to include some portion of general, including cultural, knowledge. In this it is easy to recognise some of the main features of Cognitive Semantics (suffice it to recall Lakoff's analyses, see his book of 1987). Also the attempts, especially by van Dijk and Kintsch, to understand the way in which texts are mentally processed, lead to a clearly cognitive standpoint, which would be later recognised in its full terms (see especially Rickheit (ed.) 1991; Rickheit \& Strohner 1992; Adam 1992; Bernárdez 1995b; Bernárdez to appear).

The study of text composition, also of interest for Artificial Intelligence and the automatic production of texts, lead to the emergence of the Theory of Scripts and Schemas, which was rapidly integrated in TL. Scripts and schemas are conceptual configurations of general knowledge closely related to Fillmore's frames but also to Image Schemas, etc. Since the integration and the corresponding development of this theory in the mid seventies, together with the results of Kintsch and van Dijk's studies on macrostructures, TL can be considered as cognitive from head to toe.

In an independent way, 'mainstream cognitvism' (i.e., that of American West Coast linguists like Lakoff, Fillmore, and Langacker) became also interested in the text or, as it is usually called in the Anglo-Saxon tradition, in Discourse. Books as Goldberg (ed. 1996) and Fauconnier \& Sweetser (eds. 1996) include essays on what on any account could be termed 'textlinguistic issues'. It is interesting to note that again two apparently different approaches to different linguistic phenomena lead to the same results: the need to consider language from a cognitive point of view.

\section{Categorisation (AND Biology and topology again)}

Finally, mention has to be made of the best known antecedent -and integral part- of CL: the study of categorisation in cognitive psychology. Prototype theory was a fresh answer to an old question: how are words stored in our memory, an issue that had also 
been faced by the proponents of script theory. As Prototype theory and the discussions that have surrounded it from its inception are sufficiently well-known, suffice it to remember that it again involves the need for a topological interpretation and a close relation with biology made fully explicit in Varela, Thompson, and Rosch (1991), where its connections with the proposals of the Chilean biologist, Francisco Maturana, are made clear (see also Maturana \& Varela 1990). As for topology, the conception of a category as characterised by fuzzy borders and different levels of 'centrality' corresponds quite neatly to the open sets and the different levels of potential in topological spaces and to the concept of the attractor (see Bernárdez 1995a, 1998a).

On the other hand, categorisation has proved to be inseparable from culture, thus providing the opportunity for a joint study of language and culture, something quite new in linguistics. There is no time now for a fuller treatment of this important issue, so that it must suffice to refer to such new books as Palmer (1996) and Foley (1997), although good enough examples can be found in Lakoff's Women, Fire, and Dangerous Things, as well as in some recent proposals by Ronald Langacker. This interesting development was also discernible as a promising possibility in the initial stages of modern Textlinguistics (Bernárdez 1978).

\section{ConClusion}

These notes have shown that Cognitive Linguistics can be seen as an extensive programme of research where many different approaches are possible and mutually complementary. As for the origins of this research programme, I have tried to show that Cognitive Linguistics is the result of a number of quite independent approaches to different problems of language, initially seen in different lights, although semantics and meaning have always played a fundamental role. We could go as far as saying that it was facing the problems posed by an adequate understanding of meaning that lead to Cognitive Linguistics. Along the way, the new discipline established strong contacts with other non linguistic disciplines: the role of topology as the main conceptual tool in $\mathrm{Cl}$ and its relations to psychology, not only the 'direct' ones that are a consequence of the biological nature of the brain, where cognition 'takes place', but also because biology has become the model science of the present time.

\section{REFERENCES}

Adam, J.-M. 1992. Les Textes: types et prototypes. Paris: Nathan.

Beaugrande, R. 1991. Linguistic Theory. The Discourse of Fundamental Works. London: Longman. 
Bernárdez, E. 1978. "Perspectivas de una lingüística antropológica, hoy”. Perspectivas de la antropología española. Madrid: Akal. 321-329.

Bernárdez, E. 1994. "De la 'lingüística catastrofista' a la 'lingüística cognitiva"”. Revista de Filología Alemana 2: 181-199.

Bernárdez, E. 1995a. Teoría y epistemología del texto. Madrid: Cátedra.

Bernárdez, E. 1995b. "On the study of language with the tools of Catastrophe Theory". Atlantis XVII: 261-291.

Bernárdez, E. 1996. "Predicaciones y construcciones". Alfinge 19: 79-86.

Bernárdez, E. 1998a. "Catastrophes, chaos, and lexical semantics". Lexical Semantics, Cognition and Philosophy. Ed. B. Lewandowska-Tomaszczyk. 11-28.

Bernárdez, E. 1998b. "Reflexiones sobre el texto". Unpubl. Ms.

Bernárdez, E. (to appear). "La comunidad de principios organizativos del texto y la oración". To be published in Boletín de la Academia Nacional de Letras. Uruguay, 1999.

Bouligand, Y. et al. 1994. Les sciences de la forme aujourd' hui. Paris: Éditions du Seuil. Chomsky, N. 1957. Syntactic Structures. The Hague: Mouton.

Chomsky, N. 1986. Knowledge of Language. New York: Praeger.

Chomsky, N. 1992. The Minimalist Program. Harvard (Mass.): The MIT Press.

Culicover, P. W. 1997. Principles and Parameters. An Introduction to Syntactic Theory. Oxford: Oxford University Press.

Desclès, J. \& I. Kanellos. 1997. "La notion de typicalité: une approche formelle". In: Dubois (ed.). 225-244.

Dubois, D., ed. 1991. Sémantique et cognition. Catégories, prototypes, typicalité. Paris: Éditions du CNRS.

Edelman, G. M. 1992. Bright Air, Brilliant Fire. On the Matter of the Mind. New York: Basic Books.

Ellis, J. M. 1993. Language, Thought, and Logic. Evanston, Ill.: Northwestern University Press.

Fauconnier, G. 1997. Mappings in Thought and Language. Cambridge: Cambridge University Press.

Fauconnier, G. \& E. Sweetser, eds. 1996. Spaces, Worlds, and Grammars. Chicago: University of Chicago Press.

Foley, W. A. 1997. Anthropological Linguistics. Oxford: Blackwell.

Goldberg, A. E. 1995. Constructions: A Construction Grammar Approach to Argument Structure. Chicago: The University of Chicago Press.

Goldberg, A. E., ed. 1996. Conceptual Structure, Discourse and Language. Stanford, Cal: CSLI Publications.

Guerra, J. (to appear). "A topographical visualization of the Short Story". To appear in Short Story, 1999. 
Heinemann, W. \& D. Viehweger. 1991. Textlinguistik. Eine Einführung. Tübingen: Max Niemeyer.

Jackendoff, R. 1992. Languages of the Mind. Essays on Mental Representation. Cambridge, Mass.: The MIT Press.

Jackendoff, R. 1997. The Architecture of the Language Faculty. Cambridge, Mass.: The MIT Press.

Lakoff, G. 1970. Irregularity in Syntax. New York: Holt, Rinehart and Winston.

Lakoff, G. 1977. Linguistic Gestalts. CLS 13: 236-287.

Lakoff, G. 1987. Women, Fire, and Dangerous Things. Chicago: The University of Chicago Press.

Lakoff, G. 1990. "The Invariance Hypothesis”. Cognitive Linguistics 1: 39-74.

Lewandowska-Tomaszczyk, B., ed. 1998. Lexical Semantics, Cognition, and Philosophy. Lodz: Lodz University Press.

Maturana, H. \& F. Varela. 1990. El árbol del conocimiento. Las bases biológicas del conocimiento humano. Madrid: Debate.

Palmer, G. B. 1996. Toward a Theory of Cultural Linguistics. Austin, TX: Texas University Press.

Pullum, G. K. 1991. The Great Eskimo Vocabulary Hoax and Other Irreverent Essays on the Study of Language. Chicago: The University of Chicago Press.

Radford, A. 1997. Syntax. A Minimalist Introduction. Cambridge: Cambridge University Press.

Rickheit, G., ed. Kohärenzprozesse. Opladen: Westdeutscher Verlag.

Rickheit, G. \& H. Stohner. 1992. "Towards a cognitive theory of linguistic coherence". Theoretical Linguistics: 209-237.

Talmy, L. 1977. "Rubber-sheet cognition in Language". CLS 13: 612-628.

Thom, R. 1966. Stabilité structurelle et morphogénèse. Paris: InterÉditions.

Ungerer, F. \& H. Schmidt. 1996. An Introduction to Cognitive Linguistics. London/New York: Longman.

Van Hoek, K. 1997. Anaphora and Conceptual Structure. Chicago: The University of Chicago Press.

Varela, F. J.; E. Thompson \& E. Rosch. 1991. The Embodied Mind. Cambridge, Mass.: The MIT Press. 